Geotechnical Engineering

Volume 168 Issue GE5

Stability monitoring of a rail slope using acoustic emission

Dixon, Smith, Spriggs et al.

ice | proceedings
Proceedings of the Institution of Civil Engineers

Geotechnical Engineering 168 October 2015 Issue GE5

Pages 373-384 http://dx.doi.org/10.1680/geng.14.00152

Paper 1400152

Received 06/10/2014

Published online 06/05/2015

Accepted 10/02/2015

Keywords: field testing \& monitoring/geotechnical engineering/research \&

development

ICE Publishing: All rights reserved ice

Institution of Civil Engineers

publishing

\title{
Stability monitoring of a rail slope using acoustic emission
}

1 Neil Dixon BSC, PhD, FGS

Professor of Geotechnical Engineering, School of Civil and Building Engineering, Loughborough University, Leicestershire, UK

2. Alister Smith MEng, FGS Doctoral Researcher, School of Civil and Building Engineering, Loughborough University, Leicestershire, UK

3 Matthew Spriggs BEng, PhD

Formerly Research Assisant, School of Civil and Building Engineering, Loughborough University, Leicestershire, UK
4. Andrew Ridley BSC, MSC, DIC, PhD Director, Geotechnical Observations Limited, UK

$5 \quad$ Philip Meldrum BEng

Research Engineer, British Geological Survey, Keyworth, Nottinghamshire, UK

6 Edward Haslam BSc

Electronics Engineer, British Geological Survey, Keyworth, Nottinghamshire, UK
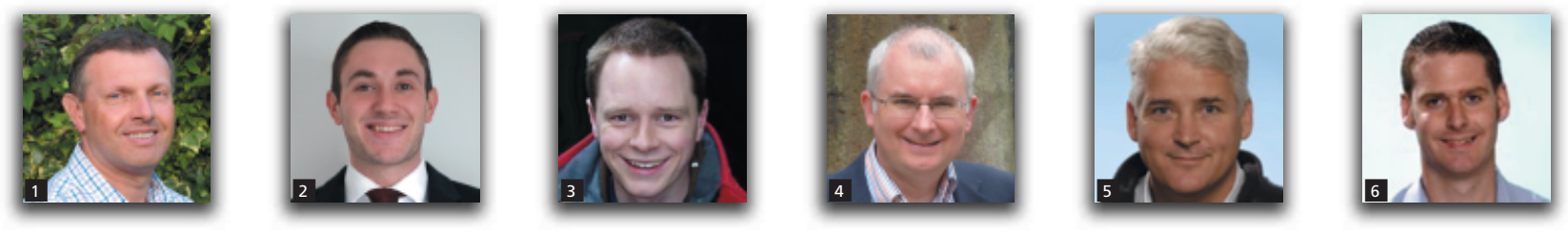

The paper details the use of acoustic emission generated by active waveguide subsurface instrumentation to monitor the stability of a rail soil cutting slope failure. Operation of the active waveguide, unitary battery-operated acoustic emission sensor and warning communication system are described. Previous field trials reported by the authors demonstrate that acoustic emission rates generated by active waveguides are proportional to the velocity of slope movement, and can therefore be used to detect changes in rates of movement in response to destabilising and stabilising effects, such as rainfall and remediation, respectively. The paper presents a field trial of the acoustic emission monitoring system at a reactivated rail-cutting slope failure at Players Crescent, Totton, Southampton, UK. The results of the monitoring are compared with both periodic and continuous deformation measurements. The study demonstrated that acoustic emission monitoring can provide continuous information on displacement rates, with high temporal resolution. The ability of the monitoring system to detect slope movements and disseminate warnings by way of text messages is presented. The monitoring approach is shown to provide real-time information that could be used by operators to make decisions on traffic safety.

\section{Introduction}

Fatalities from landslides in the UK are rare, but the cost to maintain and remediate infrastructure and the built environment as a result of slope instability is high. The operation of the UK's transport infrastructure networks (i.e. road and rail) is critically dependent on the performance of the cutting and embankment slopes through which they are constructed. A significant percentage of these geotechnical assets are rapidly ageing and suffer frequent incidents of slope instability (i.e. both first-time failures and reactivations). Slope instability poses a major safety hazard, with derailment from slope failures a significant risk faced by the operational railway. Instability and serviceability problems lead to the imposition of rail speed restrictions, highway slope repairs often lead to lane closures, and both can lead to severe travel delays. The continuing maintenance and remediation of earthworks is a major engineering and cost constraint for UK infrastructure owners. As more operational equipment such as signalling, telecoms, power and noise barriers is located within the geotechnical asset, even minor slope failures can cause major service disruption and incur significant repair costs. In addition, many hundreds of kilometres of transport links and utilities in the UK are located in areas susceptible to failure of natural slopes. Reactivated landslides in the UK that move seasonally each year (i.e. in response to intense and/or prolonged periods of rainfall, and therefore transient elevations in pore-water pressure) cause annual expenses over consecutive years of the order of millions of pounds, due to structural damage, insurance costs, engineering measures and remediation (these cost estimates relate mostly to direct effects; little information is available on indirect costs associated with disruption to traffic and the local economy) (Gibson et al., 2013). There is growing concern that climate change will result in increased frequency and severity of reactivated and first-time slope failures in the coming decades (Dijkstra and Dixon, 2010).

There is a clear need for instrumenting and monitoring existing landslides and slopes with marginal stability in order to: provide early warning of movement and of failure; provide information 
for input into analysis and remediation design; monitor landslide behaviour in response to and through construction; verify the stability of a landslide subsequent to remediation; and monitor the condition of infrastructure (in terms of serviceability and ultimate limit states) that have the potential to be affected by slope instability (Dunnicliff, 1988; Machan and Beckstrand, 2012). Examples of important parameters to monitor are: shearsurface depths; the direction and rate of mass movement; and pore-water pressures, be they positive or negative (i.e. suction), along a shear surface or potential shear surface, as these inform of transient changes to the effective stress, and therefore the stability of the slope. The total magnitude of deformation is also of interest, as a few millimetres of displacement can impact on the serviceability limit state of adjacent buildings and infrastructure. In addition, soils with strain softening characteristics can exhibit a reduction in strength subsequent to the mobilisation of peak strength in response to very small deformations, at which point high-magnitude and rapid deformations can occur (Skempton, 1964).

The cost of remediation subsequent to landslide failure is often several times higher than the cost of corrective measures and repairs if conducted prior to collapse (Glendinning et al., 2009), and this highlights the importance of slope-stability monitoring to detect the onset of instability, so that preventive works can be performed. A cost-benefit analysis is usually performed during the design of the monitoring programme to determine the most cost-effective monitoring solution. Slope-monitoring costs range from inexpensive and short term to costly and long term (Kane and Beck, 2000). The labour costs associated with manual readings of instruments are high, and are preferentially mitigated by the use of automated data-acquisition systems (Machan and Beckstrand, 2012). On the UK rail infrastructure the number of automated earthwork monitoring sites is still small, although growing in number, and the large majority of deformation instruments (e.g. inclinometers) are read manually a few times a year. This method of operation cannot provide real-time information for use in early warning.

Many different techniques and types of instrumentation are commonly used in slope monitoring. However, no single technique or instrument can provide complete information about a landslide, and therefore various combinations are usually used. Each technique or instrument has associated capital (i.e. product and installation) and operating (e.g. labour and power) costs, along with varying degrees of performance. The performance of monitoring techniques and instrumentation is often measured in terms of accuracy and precision, spatial and temporal resolution, sensitivity and reliability.

Surface deformation monitoring methods investigate the change in shape of the ground surface, and can provide measurements of the direction and rate of slope movement, and often provide high spatial resolution. Subsurface deformation monitoring methods provide the information necessary for stability assessment and remediation design. Subsurface instruments often yield high levels of accuracy, although with relatively low spatial resolution, as the instrument informs only of the soil surrounding the borehole in which it is installed. The traditional manually read inclinometer is the most commonly used instrument for subsurface deformation monitoring, and has a reported field accuracy of the order of $\pm 4-8 \mathrm{~mm}$ per $30 \mathrm{~m}$ (e.g. Abdoun et al., 2013; Mikkelsen, 2003; Simeoni and Mongiovì, 2007). This is a measure of the total error per unit length, which is composed of the random error and systematic error. Random error accumulates with the square root of the number of measurement increments, and is reported to be $\pm 1.24 \mathrm{~mm}$ over $30 \mathrm{~m}$ (Mikkelsen, 2003). Random error remains after all systematic errors have been corrected and removed, and is therefore the limit of precision possible with good practice. If only a single measurement increment is of interest, for example over a localised shear zone, accuracy of the order of $\pm 0 \cdot 2 \mathrm{~mm}$ is possible (Mikkelsen, 2003). Traditional inclinometers provide relatively high resolution with depth, as measurements are recorded at $0.5-1 \mathrm{~m}$ increments. However, it is an interval monitoring instrument, and offers relatively low temporal resolution as measurements can only be taken when the casing is manually surveyed.

The advent of in-place inclinometers overcame this problem, as a probe string or an individual probe (installed at the shear surface depth once the depth has been determined from manual surveys) can $\log$ data continuously and with high temporal resolution (i.e. at user-defined time intervals ranging from minutes to hours). A recent development is the ShapeAccelArray (SAA) (e.g. Abdoun et al., 2013 and Smith et al., 2014a detail case histories where the SAA has been used), which comprises a string of microelectro-mechanical systems (MEMS) sensors installed at regular increments along the length of a borehole (available SAA gauge lengths are $0 \cdot 2,0 \cdot 305$ and $0.5 \mathrm{~m}$ ). The SAA monitors subsurface deformations continuously and with high temporal resolution. The accuracy reported in the literature for the SAA is $\pm 1.5 \mathrm{~mm}$ per $30 \mathrm{~m}$ (e.g. Abdoun et al., 2013). In-place inclinometers and SAAs can also provide remote real-time information if connected to a communication system. Another consideration is the operational life of such subsurface instrumentation. Localised shear surface displacements of the order of $50 \mathrm{~mm}$ have been sufficient to induce excessive bending within inclinometer casings and render them unusable (i.e. the torpedo probe can no longer pass the shear surface), although shear surface displacements of the order of $100 \mathrm{~mm}$ are more typical. In contrast, shear surface displacements in excess of hundreds of millimetres have been recorded using SAA systems (Dasenbrock, 2014).

There is a need for affordable instrumentation that can provide continuous, remote, real-time information with high temporal resolution on slope movements in order to provide early warning of instability for use in the protection of people and infrastructure by practitioners. The term 'continuous' is used in the present paper to describe measurements that are automatically recorded at regular intervals of the order of minutes (in contrast to manual 
measurements taken periodically at intervals of weeks or months), and the term 'real-time' is used to describe the automatic communication of information immediately after it has been detected (in contrast to this information being available subsequent to data downloads and analysis). The Assessment of Landslides using Acoustic Real-time Monitoring Systems (Alarms), which are based on detecting and quantifying the acoustic emission (AE) generated by an active waveguide installed through a deforming soil slope, has been developed and trialled using unitary battery-operated sensors.

This paper describes the $\mathrm{AE}$ measurement system and the associated communication system that is used to disseminate warnings of movement based on trigger levels related to slopedisplacement rates. Measurements from long-running field trials in the UK are used to demonstrate the performance of the method, and a case study of Players Crescent, Southampton, UK, is detailed as an example of where the AE monitoring system is being used to monitor the stability of a cutting slope that threatens continued operation of a rail line.

\section{AE monitoring system}

\subsection{Active waveguide}

Deformation within soil generates interparticle friction and AE. Particle-particle interactions (e.g. sliding and rolling friction) and rearrangement of the particle-contact network (e.g. release of contact stress and stress redistribution as interlock is overcome and regained) are mechanisms that generate $\mathrm{AE}$ within soil (Lord and Koerner, 1974; Michlmayr et al., 2012a, 2012b, 2013). Research has shown that soil-generated $\mathrm{AE}$ is detectable and measurable. The characteristics of the AE generated are governed by the properties of the soil (e.g. AE from fine-grained soils is highly influenced by moisture content and plasticity, and $\mathrm{AE}$ events of greater magnitude are produced in granular soil with large angular particles), and $\mathrm{AE}$ events with greater magnitude are generated by deforming soil with high interparticle contact stresses (Garga and Chichibu, 1990; Koerner et al., 1981; Michlmayr et al., 2013; Mitchell and Romeril, 1984; Shiotani and Ohtsu, 1999).

Various authors have used AE monitoring to assess the stability of both natural and constructed slopes (e.g. Beard, 1961; Cadman and Goodman, 1967; Chichibu et al., 1989; Dixon et al., 2003, 2014a, 2014b; Fujiwara et al., 1999; Naemura et al., 1991; Nakajima et al., 1991; Rouse et al., 1991; Smith et al., 2014a, 2014b). Fine-grained soils generate relatively low-energy AE signals, which attenuate significantly over short distances. In order to monitor the AE generated by deforming slopes formed of fine-grained soils, Dixon et al. (2003) devised the active waveguide. The active waveguide (Figure 1) is installed in a borehole that penetrates any shear surface or potential shear surface beneath the slope; it comprises a steel waveguide (i.e. to transport the AE signals generated at the shear surface to the ground surface with relatively low resistance) and angular gravel

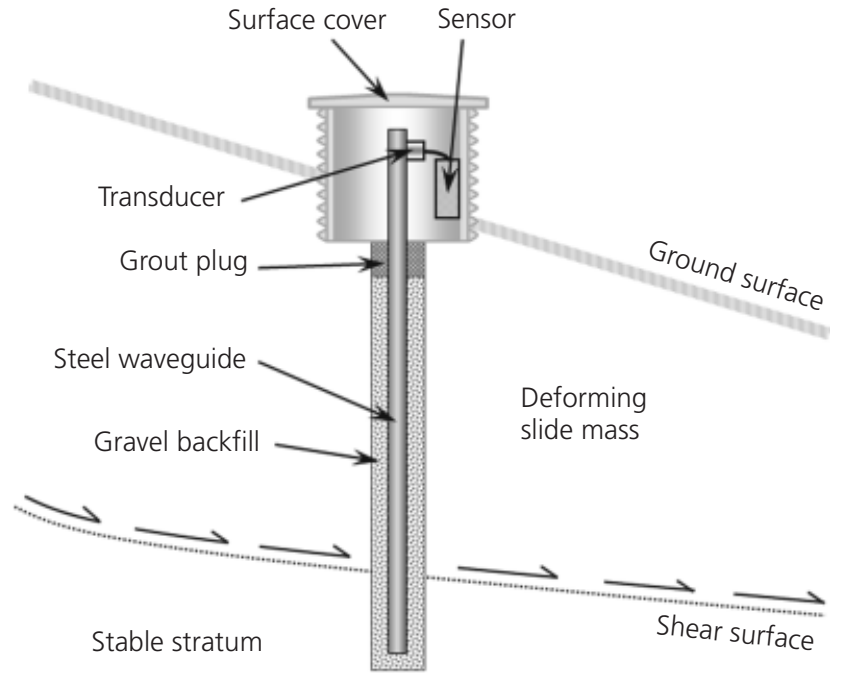

Figure 1. An active waveguide installed through a slope deforming on a shear surface, with an AE monitoring sensor attached to the top of the waveguide and protected by a cover (after Dixon et al. (2012a))

backfill (i.e. to generate relatively high-energy $\mathrm{AE}$ as the slope deforms, which can propagate along the waveguide). As the slope displaces, the gravel backfill is deformed, generating the AE.

\subsection{AE sensor and communication system}

Figure 2 details the operation of the monitoring system. AE generated by the active waveguide in response to slope movement is detected by the transducer coupled to the waveguide at the ground surface, and is converted to an electrical signal (by way of the piezoelectric effect). The battery-operated Slope Alarms sensor (Dixon and Spriggs, 2011) is a unitary system in that all components are housed together, unlike earlier PC-based systems (e.g. Dixon et al., 2003). The sensor amplifies, filters and processes the AE signals. Ring-down counts (RDC) are detected (using a comparator), recorded and time stamped for each monitoring period (this can range from $5 \mathrm{~s}$ to $60 \mathrm{~min}$ ). RDC are the number of times the AE signal amplitude (converted to a series of all positive values) crosses a programmable voltagethreshold level within a predetermined time period. There are several benefits of monitoring RDC over the entire AE waveform. Monitoring RDC reduces the amount of processing power and storage capacity required by the battery-operated sensor, which is critical in ensuring its long operating life, lower cost and portability. This is because waveform processing can be incorporated in the analogue part of the system, rather than having to digitise the high-frequency signal, which would require high processing speeds, and hence high power requirements. It is possible to set the voltage threshold level greater than the amplitude of the ambient background noise, thus providing the ability to remove unwanted information. The ability to record one number (i.e. an RDC value) next to each time stamp removes the necessity for complex interpretations (i.e. user-friendly) and 


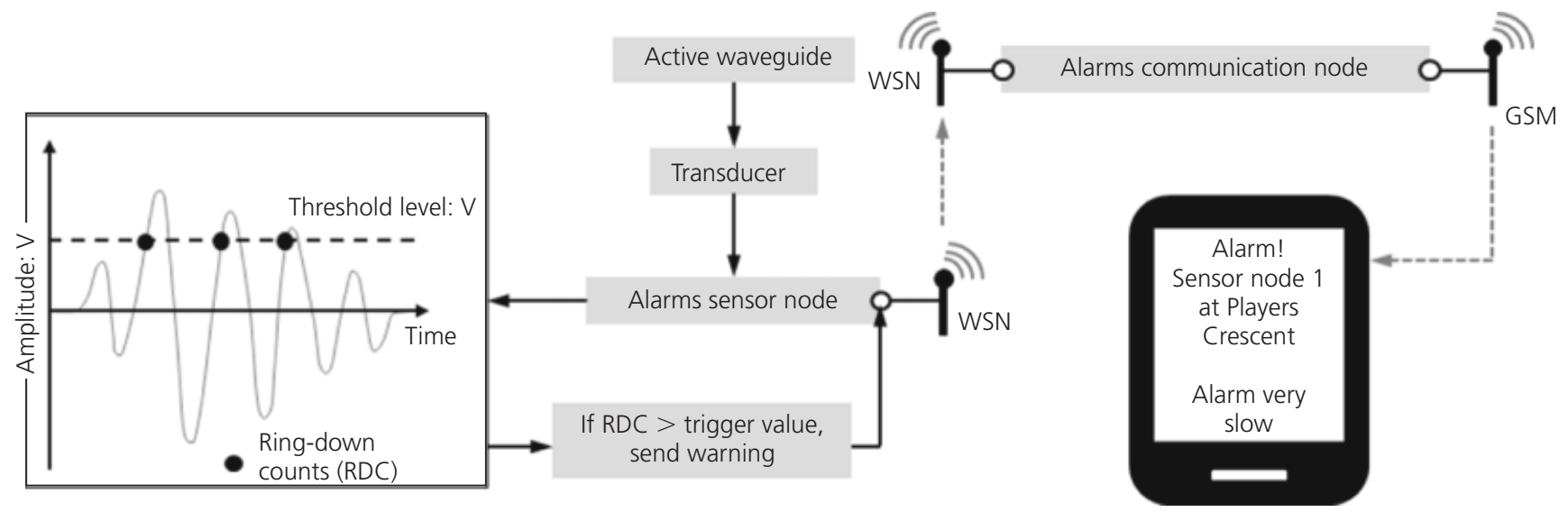

Figure 2. The operation of the AE monitoring and communication system

allows simple warning trigger levels to be set. Another key design aspect of the Slope Alarms sensor is the use of filters to focus $\mathrm{AE}$ detection within the frequency range $20-30 \mathrm{kHz}$, which eliminates low-frequency $(<20 \mathrm{kHz})$ environmental noise (such as that generated by wind, traffic and construction activities), while retaining soil-generated $\mathrm{AE}$ that is within this frequency range (e.g. Dixon et al., 2003; Koerner et al., 1981). This produces a robust system and minimises the potential for false alarms.

Previous research (e.g. Dixon and Spriggs, 2007; Smith and Dixon, 2014; Smith et al., 2014a) has shown that AE rates (i.e. RDC generated per unit time) generated by an active waveguide in response to slope movement are directly proportional to the rates of slope movement (i.e. velocity). This is because an increasing rate of deformation (i.e. in response to increasing slope velocity) within the active waveguide generates an increasing number of particle-particle/particle-waveguide interactions. Each of these interactions generates a transient AE event. These transient $\mathrm{AE}$ events combine and propagate along the waveguide, where they are monitored by the sensor at the ground surface. Hence, AE rates produced and measured by the system are proportional to the velocity of slope movement. Through calibrations in the laboratory (e.g. Dixon and Spriggs, 2007; Smith and Dixon, 2014) it is possible to set RDC warning trigger levels that are indicative of slope-displacement rates, separated by orders of magnitude (e.g. slow $-1 \mathrm{~mm} / \mathrm{h}$, moderate $-100 \mathrm{~mm} / \mathrm{h}$, rapid $10000 \mathrm{~mm} / \mathrm{h}$ ), which is in line with standard classifications of landslide movements (e.g. Anderson and Holcombe, 2013; Cruden and Varnes, 1996; Schuster and Krizek, 1978). If a Slope Alarms sensor detects RDC within a set time period that exceeds a trigger warning level, the sensor transfers this information to the communication system through a wireless network link. The communication system subsequently sends a SMS message to responsible persons so that relevant action can be taken (e.g. send an engineer to inspect the slope, or immediately stop traffic). The absence of generated SMS messages means that the slopedisplacement rates are lower than the minimum threshold set. Automatically generated daily SMS messages provide information on the status of the system, demonstrating it is operational. The system therefore provides continuous real-time information on slope-displacement rates with high temporal resolution (i.e. monitoring periods are typically 15 or $30 \mathrm{~min}$ ).

\subsection{Interpretation of measured AE behaviour}

Figure 3(a) shows continuous cumulative RDC-time and deformation-time series measurements from an active waveguide and SAA installed through a reactivated natural soil slope (data taken from Smith et al., 2014a) in response to a series of slide movements. The shape of both the cumulative RDC-time and deformation-time series are characteristic of reactivated S-shaped slope movements (e.g. Allison and Brunsden, 1990; Petley et al., 2005). The series of slide movement events is preceded by periods of rainfall that induced transient elevations in pore-water pressures along the shallow shear surface. Figures 3(b) and 3(c) show the SAA velocity-time and the AE rate-time series of measurements from this period of slide movements. It can clearly be seen that the $\mathrm{AE}$ rate-time and velocity-time series are proportional to one another (Figures 3(b) and 3(c)). These measurements were analysed in further detail by Smith et al. (2014a), where determination of an $\mathrm{AE}$ rate-velocity relationship produced an $R^{2}$ value of 0.8 from a linear regression. During the reactivation events, both the velocity of the sliding mass and the $\mathrm{AE}$ rates generated by the active waveguide increase until they reach a peak, at which point they subsequently decay exponentially as the slope and active waveguide backfill become stable. It should be noted that the response of the system to first-time slope failures (i.e. development of a full shear surface during progressive failure and eventual collapse as a result of brittle strength loss) is expected to result in a continuous increase in AE rates as the velocity of slope movement increases throughout the failure event. 


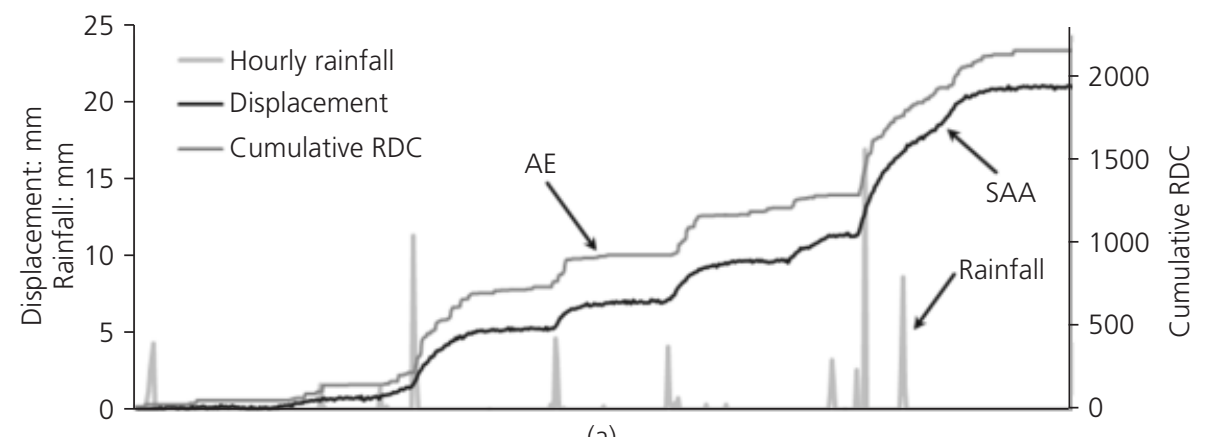

(a)

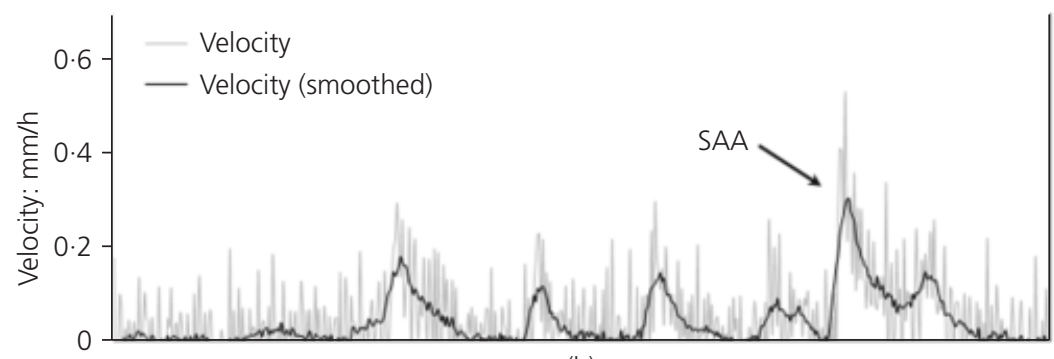

(b)

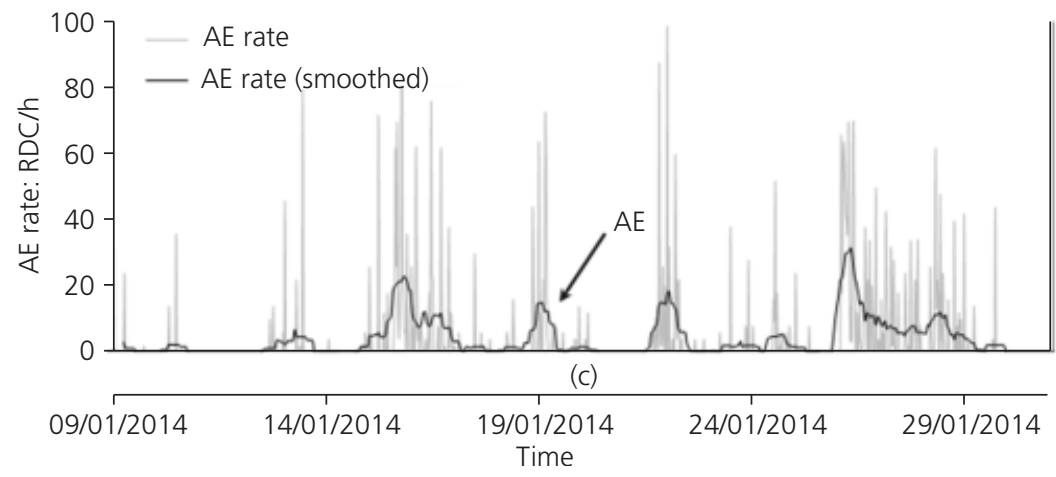

Figure 3. A series of measurements for a period of reactivated slope movements (after Smith et al., 2014a): (a) cumulative RDC, displacement and hourly rainfall over time; (b) velocity and smoothed velocity over time; (c) AE rate and smoothed AE rate over time

\section{Players Crescent field trial}

\subsection{Introduction}

In order to evaluate the performance of the $\mathrm{AE}$ monitoring system it is important to conduct trials in typical field environments. The Players Crescent field trial was designed to investigate the capability of Slope Alarms to provide real-time information that could be used by operators to make decisions on traffic safety. A reactivated cutting slope at Players Crescent, Totton, Southampton, UK, was selected for a field trial, as in recent years slope deformations have occurred during the winter months, and there was confidence that measurable slope deformations would take place during the planned trial period. A single rail track is located at the toe of the slope servicing the Southampton docks area. It is lightly trafficked (i.e. a few trains per day) by lowspeed goods trains (limited to $30 \mathrm{mph}$ [48.28 kph]).

\subsection{Site description}

The dominant geology in which the slope at Players Crescent is formed is the Barton Clay Formation (BCF), which is overlain by the Chama Sand Formation (CSF). The CSF terminates a few metres below ground level at the top of the slope, and is not present at the toe of the slope. A site investigation undertaken in March 2009 revealed a soft to firm horizon (in the BCF) at a depth of 6-7 $\mathrm{m}$ in the borehole in which the upper inclinometer casing was installed (subsequent monitoring has shown this to be the depth of the shear surface at this location, Section 3.4). During visual inspection at the site it was noted that a previous slope failure had occurred on the opposite side of the rail line where a sheet pile wall had been constructed as part of the remediation effort, demonstrating that multiple earthworks instabilities have occurred along this section of track. The initial 
visual inspection of the site also revealed the presence of convex young saplings on the crown of the monitored slope, which indicated that creep movements were taking place within the over-steep surficial CSF. Semi-mature, back-tilted trees present below the main scarp indicate rotational slope movements and, therefore, a curved shear surface. A possible second scarp present further down the slope suggested that the landslide was possibly compound with multiple failure surfaces.

The reactivated slide mass was interpreted as moving along a defined shear surface that was at, or close to, residual strength (and therefore little or no further brittle loss of strength could take place), which was expected to result in small, low-velocity movements in response to seasonal pore-water pressure fluctuations inducing oscillations in shear strength along the shear surface (Hutchinson, 1988; Leroueil, 2001). Therefore, rapid and catastrophic failure was not anticipated; however, bulging at the toe of the slope was a concern, due to interaction with the adjacent rail infrastructure (i.e. serviceability limit state). A concrete cable trough at the toe of the slope had been deformed, indicating continued movement (Figure 4).

\subsection{Instrumentation installation}

The site plan shown in Figure 5 details the locations of the instruments that were installed along a cross-section of the slope. The current study used the central two inclinometer casings that were installed in May 2009 as part of an array of six on this slope, and were typically read twice a year. The inclinometer casing (up-slope) was installed to a depth of $7.5 \mathrm{~m}$ below ground level. A SAA string (down-slope) with a MEMS sensor spacing of $0.305 \mathrm{~m}$ was installed in the lower inclinometer casing to a depth of $5 \mathrm{~m}$ below ground level. This converted the manually read instrument into a continuously read system. The annulus around the inclinometer casings and the SAA access tubing were grouted using medium-stiffness cement-bentonite grout (approx-

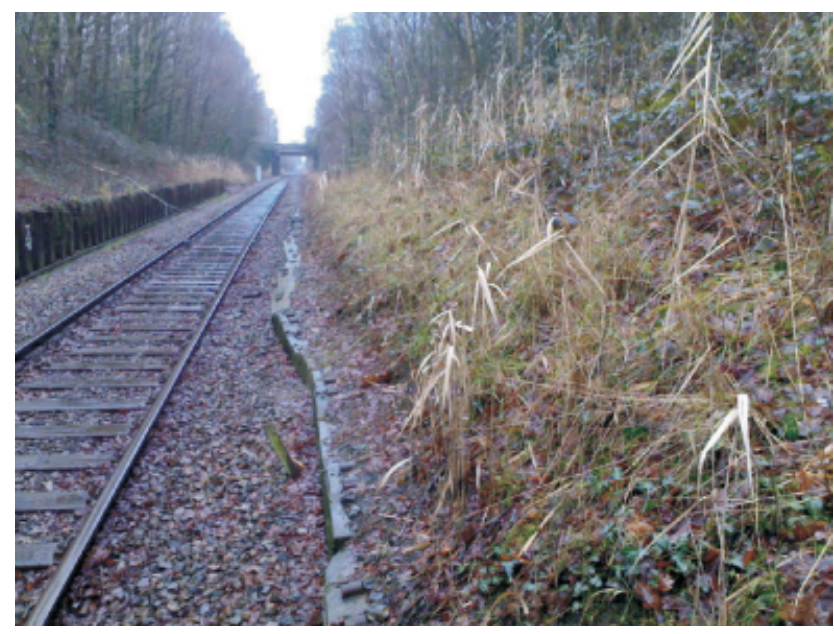

Figure 4. The toe of the slope, showing the distorted concrete cable trough and toe bulging

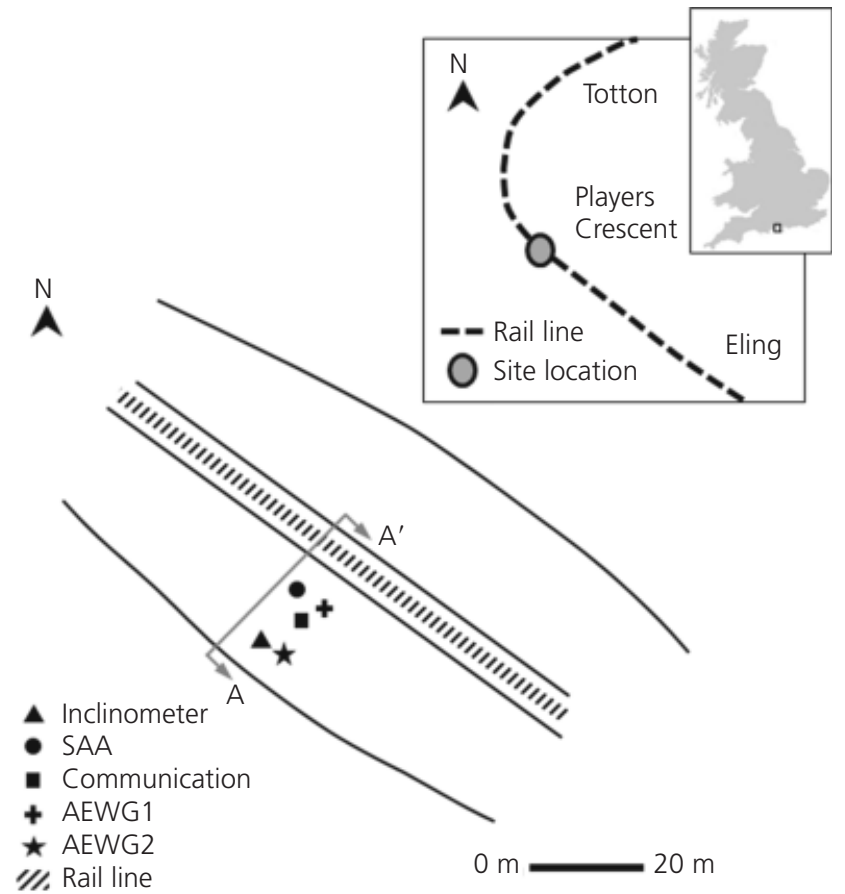

Figure 5. Site plan and instrumentation locations (cross-section A$A^{\prime}$ is shown in Figure 8)

imate water, cement and bentonite proportions by mass were 1 , $0 \cdot 15$ and $0 \cdot 06$, respectively). The SAA was powered by a battery and connected to a data logger (all secured under a protective surface chamber) that logged changes in the position of each of the MEMS sensors in the $x$-, $y$ - and $z$-directions at $1 \mathrm{~h}$ intervals. Active waveguides were installed adjacent to both of these subsurface deformation monitoring instruments. The active waveguides were installed in $130 \mathrm{~mm}$ diameter boreholes; the downslope active waveguide (AEWG1) was installed to a depth of $5.7 \mathrm{~m}$ adjacent to the SAA, and the up-slope active waveguide (AEWG2) was installed to a depth of $8.9 \mathrm{~m}$ adjacent to the inclinometer casing. The waveguides comprise $3 \mathrm{~m}$ lengths of $50 \mathrm{~mm}$ diameter $3 \mathrm{~mm}$ thick steel pipe connected with screwthreaded couplings. The annulus around the steel pipes was backfilled with angular $5-10 \mathrm{~mm}$ gravel compacted in nominally $0.25 \mathrm{~m}$ high lifts. The top $0.3 \mathrm{~m}$ of the boreholes was backfilled with bentonite grout to produce a plug and seal against the infiltration of surface water. The steel pipes extend $0.3 \mathrm{~m}$ above ground level so that the transducers can be coupled, and are encased in secure protective chambers. An additional protective chamber was installed to house the communication system. Figure 6 shows a photograph of the down-slope surface covers taken from the bottom of the slope. The Slope Alarms sensors measure the $\mathrm{AE}$ continuously and $\log$ the number of RDC at 30 min intervals. The $\mathrm{AE}$ sensors and communication system were powered using air-alkaline batteries. AE monitoring commenced in February 2011. 
Stability monitoring of a rail slope using acoustic emission

Dixon, Smith, Spriggs et al.

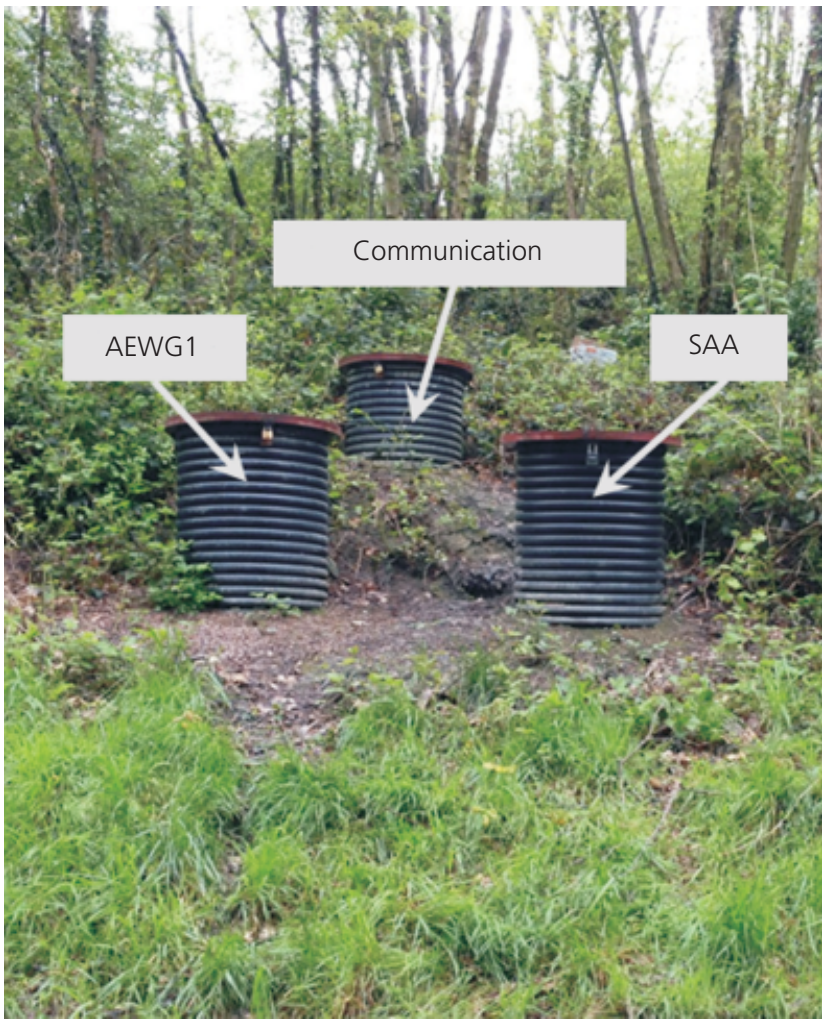

Figure 6. Photograph from the bottom of the slope, showing the surface covers protecting AEWG1, the SAA and the communication node

\subsection{Deformation history}

Figure 7(a) presents survey data from the inclinometer casing and Figure 7(b) survey data from the SAA. The data show a shear surface depth at the location of the inclinometer of approximately $6.5 \mathrm{~m}$ (agreeing with the location of the soft to firm horizon found in the site investigation, as described in Section 3.2) and a shear surface depth of approximately $3 \mathrm{~m}$ at the location of the SAA. This information was used to produce the cross-section of the slope shown in Figure 8 (section $\mathrm{A}-\mathrm{A}^{\prime}$ in Figure 5) and the interpretation of the location and geometry of the shear surface, which was assumed to intersect the rear scarp and the toe.

\subsection{AE and deformation comparison}

Figure 9(a) shows cumulative RDC, deformation and hourly rainfall over time for a period of slope movement that occurred between 19 April and 5 May 2012. The continuous deformation information was recorded by the SAA installed down-slope (i.e near the toe). Deformation data were taken from the MEMS sensor immediately above the shear surface depth, and the measurements shown are the resultant from both $x$ - and $y$ directions (i.e. resultant horizontal displacement). The $\mathrm{AE}$ data were recorded by the adjacent active waveguide and sensor node (AEWG1). Figure 9(b) shows the AE rate time series superimposed on top of the same deformation event. Approximately $1.2 \mathrm{~mm}$ of slope movement occurred during this 16 day period.
Displacement: $\mathrm{mm}$

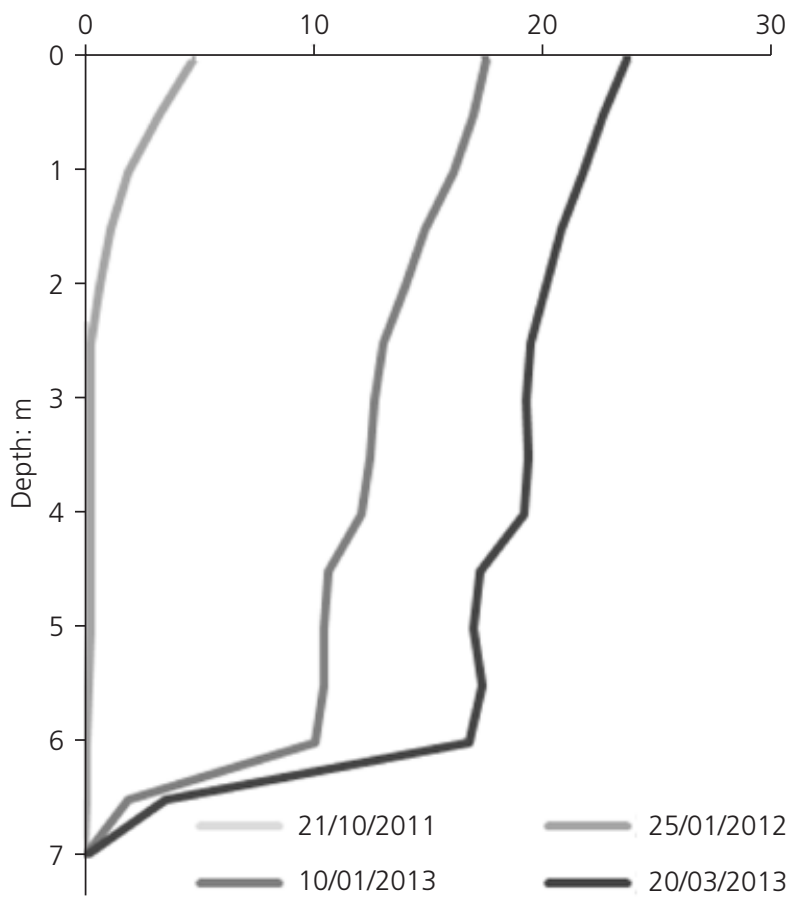

(a)

Displacement: $\mathrm{mm}$

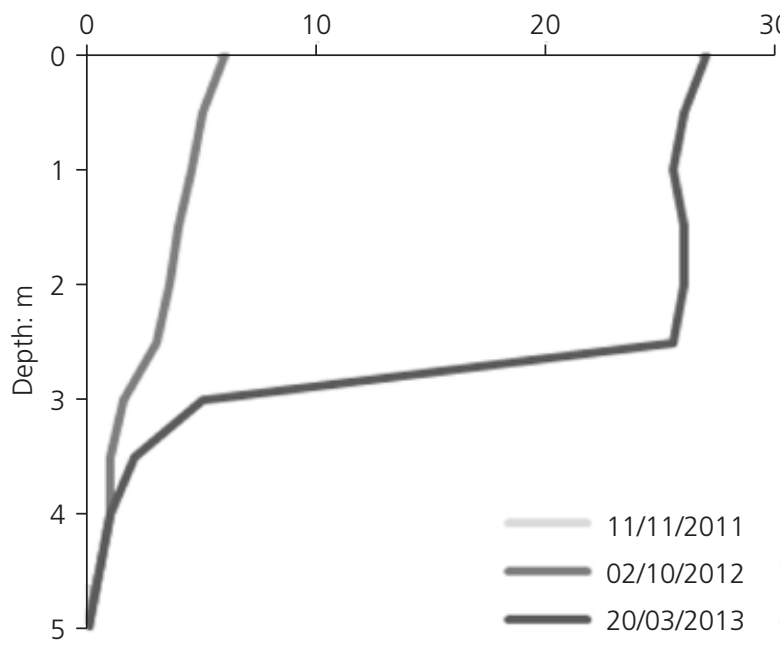

(b)

Figure 7. (a) Selected inclinometer survey data (0, initial reading on 21 October 2011) showing the main shear surface at a depth of approximately $6.5 \mathrm{~m}$ in the upper part of the slope, and (b) selected SAA survey data (0, initial reading on 11 November 2011) showing the main shear surface at a depth of approximately $3 \mathrm{~m}$ in the lower part of the slope. Note that the deformations increased progressively with time

The gradient of the SAA deformation-time series during the event was relatively constant, and therefore the velocity of movement was relatively constant. Thus the velocity can be determined using the displacement-time relationship, and this 


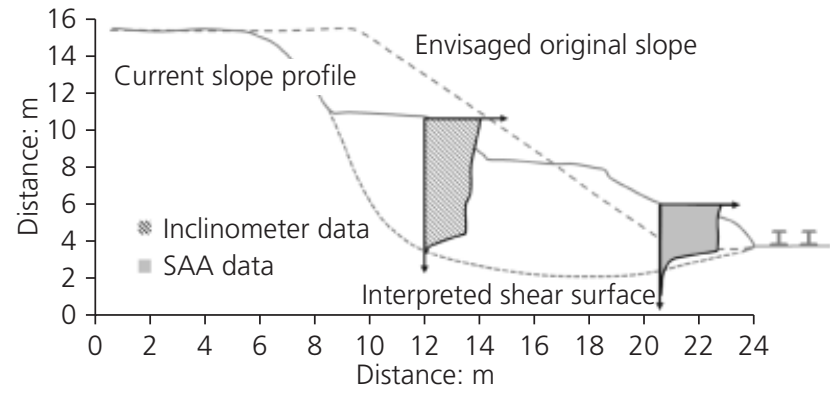

Figure 8. Cross-section A-A' (see Figure 5) showing the envisaged original slope profile, the current slope profile and the interpreted shear surface (with exaggerated inclinometer and SAA data)

generates values of $0.075 \mathrm{~mm} / \mathrm{d}$ or $0.003 \mathrm{~mm} / \mathrm{h}$; these rates of movement would be classified as 'very slow' according to Anderson and Holcombe (2013) and Cruden and Varnes (1996). Although there are fluctuations in the measured values, this event demonstrates the ability of the SAA to detect and quantify such low-velocity and small-magnitude movements continuously, with high temporal resolution.
The active waveguide and sensor node also detected this small, low-velocity slope movement event. Of particular interest is the dramatic continual increase in $\mathrm{AE}$ rates as the slope movement initiated, and this continued throughout the 'very slow' deformation event. A surge of accelerated movement between 29 April and 30 April occurred in response to a preceding period of intensive rainfall. This period of accelerated movement was detected by the AE system, as evidenced by the increased $\mathrm{AE}$ rates (Figure 9b) throughout this period, and the increased gradient of the cumulative RDC record (Figure 9a).

The AE system produced continuous information with high temporal resolution, which demonstrates the potential of the system to provide alternative deformation rate information to detect and provide an early warning of slope movements. The ability of the AE system to detect such small, low-velocity slope movements highlights its potential for use as an early warning system. Unfortunately, the AE data ended on 3 May 2012 (due to reaching storage capacity on the data logger), and so the final 2 days of the deformation event were not monitored, however; based on monitoring trends from similar events at other sites, it is expected that the $\mathrm{AE}$ rates generated by the active waveguide would have reduced as the rate of slope movement reduced, and the gradient of the cumulative RDC curve would gradually
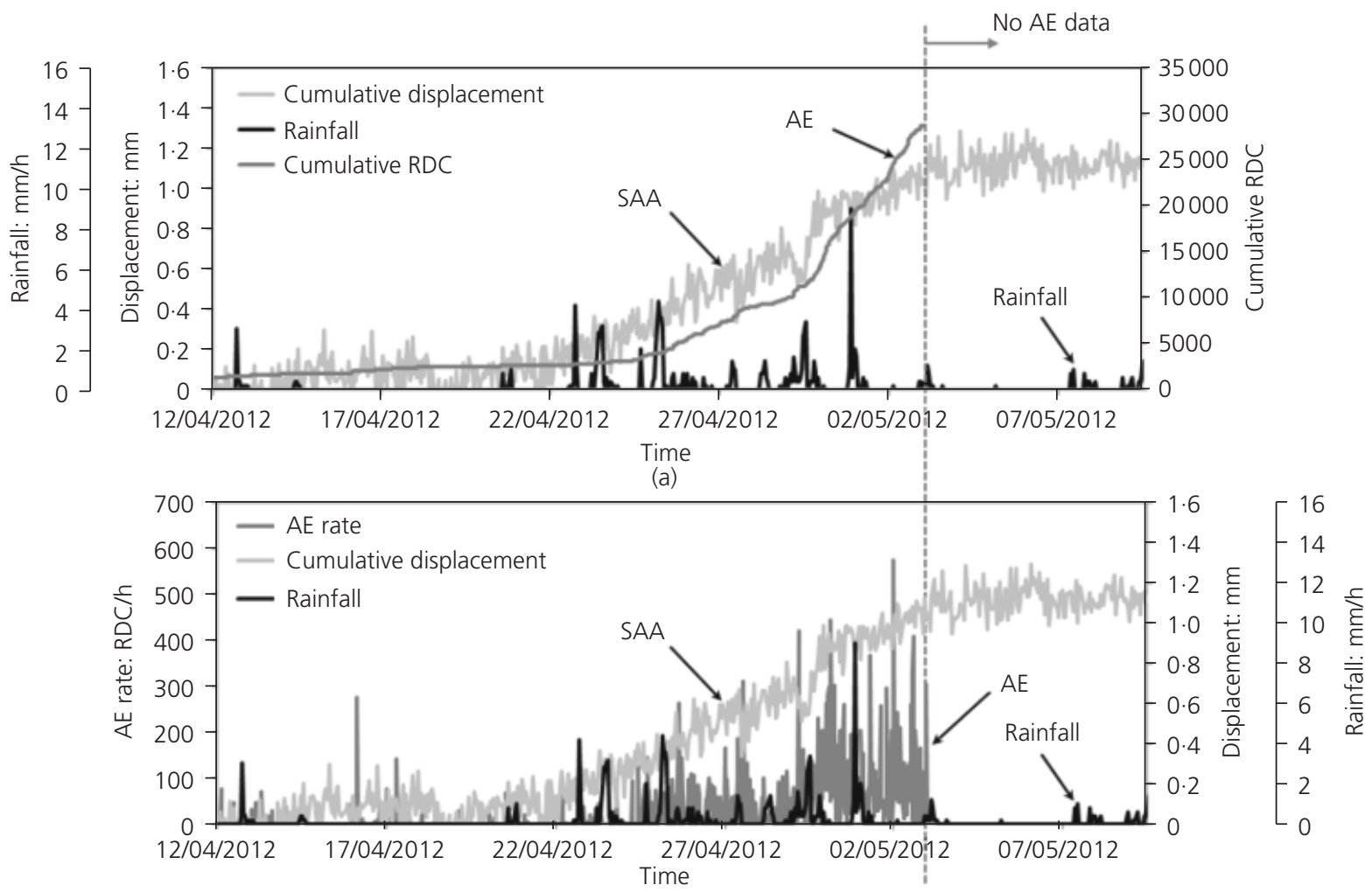

(b)

Figure 9. (a) Cumulative RDC, displacement and hourly rainfall against time for a small-magnitude, low velocity reactivated deformation event (data from the SAA and AEWG1), and (b) $A E$ rate $(R D C / h)$, displacement and hourly rainfall against time (data from the SAA and AEWG1) 
decrease and become horizontal as deformation ceased and the column of gravel backfill approached equilibrium (as in the slope movement events shown in Figure 3).

\subsection{Early warning of slope movement}

Predefined trigger levels were set on the sensors related to displacement rates. If the measured RDC in any given monitoring period exceeded one of the trigger levels, a SMS message was generated. The communication system sent a SMS alarm status on 24 November 2012 at 7:00 p.m., which stated that AEWG1 had detected 'very slow' movement as the AE rate exceeded $2000 \mathrm{RDC} / \mathrm{h}$ (Figures 10 and 11). Another SMS was sent on 25 November 2012 at 6:30 a.m., which stated that AEWG2 had also detected 'very slow' movement (both messages were received by the authors' mobile phones, one of whom was in Peru at the time) (Figure 11). Only one text message was generated at each of the two instrument locations during this period of movement because the $\mathrm{AE}$ rates subsequently decreased beneath the lowest trigger threshold in the successive measurement intervals. These warnings were generated by the peaks in the bell-shaped AE rate-time curves shown in Figure 10, which are characteristic of deformation events (as described in Section 2.3). Figure 10 shows the AE rate, inclinometer displacement and hourly rainfall over time for the period in which the deformation events and alarm SMS messages were triggered. The $11.5 \mathrm{~h}$ that separated the warning messages indicated that movement had been detected in the lower part of the slope prior to being detected in the upper section of the slope. Subsequent interrogation of the data shown in Figure 10 confirmed that the toe of the slope indeed moved before the head (i.e. AEWG1 generated a bell-shaped AE rate curve prior to AEWG2). An extended period of intense rainfall occurred at the location of the site prior to, and during, the deformation events. This rainfall provided for a build-up of pore-water pressures in the vicinity of the shear surface that was sufficient to reduce the effective stress and induce movement. This was followed by a deceleration of movements as pore-water pressures dissipated and due to mobilisa-

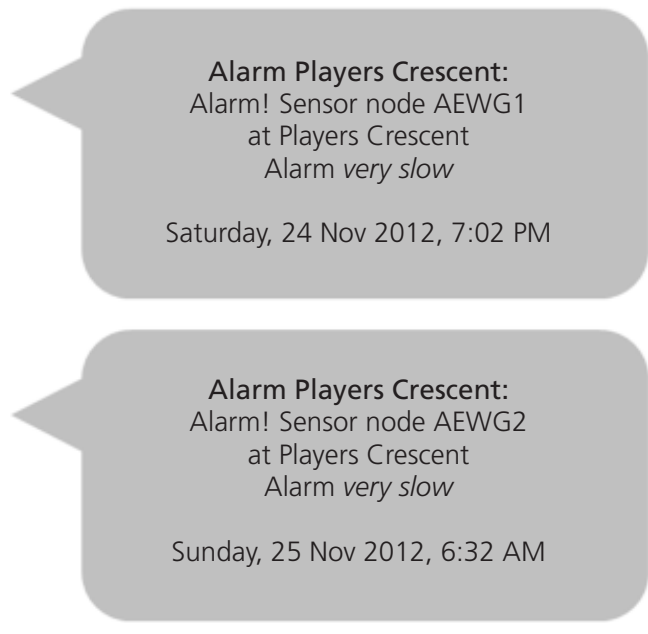

Figure 11. SMS warning messages AEWG1 (lower waveguide) and AEWG2 (upper waveguide) (Figure 10) showing the information contained (e.g. the time stamps and the alarm status)

tion of shear resistance internally in the slide mass and through remoulding at the landslide toe. Unfortunately, the SAA data logger reached storage capacity prior to this period, and therefore continuous deformation data were not available for comparison. However, interpretation of inclinometer measurements made between 15 November 2012 and 10 January 2013 (Figure 10) confirmed that deformation had occurred during this period, but the rate of movements over time is unknown. This episode has demonstrated the ability of the Slope Alarms AE monitoring system to detect and communicate warnings of slope movements.

\section{Performance of the AE monitoring system}

AE monitoring of active waveguides using a system such as Slope Alarms is able to differentiate rates of slope movement to greater than an order of magnitude (e.g. able to differentiate

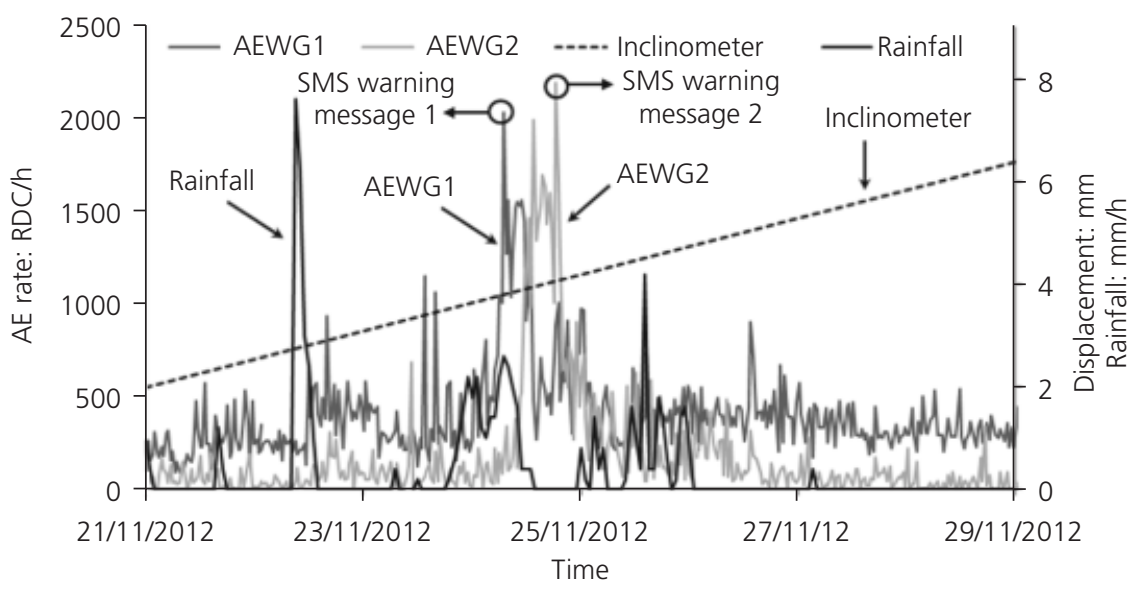

Figure 10. $A E$ rate $(R D C / h)$, inclinometer displacement interpreted for the measurement interval 15 November 2012 to 10 January 2013 and hourly rainfall against time for a period of slope movement in response to intensive rainfall (data from AEWG1, AWEG2 and the inclinometer), the timing of the SMS warning messages (Figure 11) are superimposed 
between $0 \cdot 001,0 \cdot 01,0 \cdot 1,1$ and $10 \mathrm{~mm} / \mathrm{h}$ ) (Smith and Dixon, 2014), and is therefore consistent with standard classification of landslide movements and able to detect changes in rates of movement (i.e. accelerations and decelerations) in response to destabilising (i.e. rainfall) and stabilising (i.e. pore-water dissipation and remediation) effects. The overarching function of the $\mathrm{AE}$ monitoring system described is to provide an early warning of slope instability through detecting, quantifying and communicating accelerations of slope movement. Conventional inclinometers are unable to provide this level of information because they do not monitor rates of displacement continuously or provide warnings of instability. AE rates increase instantaneously in response to a decrease in slope stability, and are sensitive to small magnitudes of displacement and very slow rates of displacement (Smith et al., 2014a); the study at Players Crescent confirmed this through comparisons with continuous SAA deformation measurements during a movement event of $0.075 \mathrm{~mm} / \mathrm{d}$.

The approach provides high temporal resolution as monitoring is continuous at user-defined measurement intervals (of the order of minutes). Resolution with depth provided by the instrumentation is relatively low as it is not currently able to locate shear surfaces; however, if the sensor was able to digitise the entire waveform it would be possible to differentiate arrival times of various AE wave modes propagating along the waveguide in order to locate the shear surface (as described by Spriggs, 2005). The system operates at significantly larger shear surface displacements than conventional inclinometers; active waveguides have continued to operate beyond shear surface deformations in excess of $400 \mathrm{~mm}$ and are expected to continue to operate at significantly larger deformations. With regard to reliability, Slope Alarms installations have continued to operate in the field environment for durations in excess of 5 years without any deterioration in performance.

The main cost associated with the $\mathrm{AE}$ system, as with most subsurface instrumentation, is with drilling the borehole, and this cost is the same as for other subsurface instrumentation. Installation costs associated with the subsurface materials (i.e. waveguide and backfill) are comparable to those for installing inclinometer casings. The cost of an Alarms sensor and transducer are comparable to a data-logger and, as they are kept above ground level, can be reused at other installations (i.e. are not sacrificial). The provision of a real-time warning system can be incorporated at a monthly cost comparable to a mobile phone SIM contract.

\section{Ongoing research}

Field trials of the Slope Alarms monitoring approach at multiple sites are currently ongoing in order to further assess the performance of the system in a range of field environments. Slopes that are being monitored using Slope Alarms include: coastal cliffs in north-east England (e.g. Dixon et al., 2014b); natural landslides in north-east England (e.g. Dixon et al., 2014a; Smith et al., 2014a); a highway infrastructure slope in Alberta, Canada (e.g. Smith et al., 2014b); a rail infrastructure slope in Austria; and a rock slope in the eastern Italian Alps, which poses a risk to highway infrastructure (e.g. Dixon et al., 2012b). Large-scale experimentation is also planned for the near future to assess the performance of the system in monitoring and providing early warning of firsttime landslide failures (as opposed to the reactivated landslides that are currently being monitored, which experience movement events of modest speed and travel). In addition, Smith et al. (2014c) have demonstrated that active waveguides can be installed inside existing inclinometer casings to provide subsurface realtime monitoring at relatively low cost by using the existing subsurface infrastructure in the slope. The benefits of retrofitting inclinometer casings with such a system include the provision of continuous real-time information on slope movements, and continued operation beyond displacements that would normally be sufficient to render inclinometer casings unusable (i.e. not allow the torpedo probe to pass the shear surface).

\section{Summary}

This study looked at the use of active waveguides as subsurface instrumentation to monitor $\mathrm{AE}$ generated in response to slope movements, and to assess the stability of soil slopes. The operation of the active waveguide, the unitary battery-operated Slope Alarms sensor and communication system have been described. Previous field trials reported by the authors have demonstrated that $\mathrm{AE}$ rates generated by active waveguides are proportional to the velocity of slope movement, and can therefore be used to detect changes in rates of movement (i.e. accelerations and decelerations) in response to destabilising (i.e. rainfall) and stabilising (i.e. pore-water dissipation and remediation) effects. A field trial was undertaken at a reactivated rail cutting soil slope at Players Crescent, Totton, Southampton, UK. The results demonstrate the performance of $\mathrm{AE}$ monitoring of active waveguides to provide continuous information on slope-displacement rates with high temporal resolution. The study confirmed the ability of the Slope Alarms system to detect slope movements of slow rate and small magnitude, and communicate warnings by way of an SMS message, based on trigger levels indicative of slope-displacement rates. The messages can be used to initiate relevant action such as sending an engineer to inspect the site or controlling train access to the section of track. The field trial has demonstrated the capability of Slope Alarms to provide real-time information that could be used by operators to make decisions on traffic safety.

\section{Acknowledgements}

The authors extend their sincerest gratitude to Derek Butcher (Network Rail) for his help in the selection of the trial site and for making the site works possible. The Engineering and Physical Sciences Research Council (EPSRC), UK, funded much of the Slope Alarms research and development. Meldrum and Haslam publish with the permission of the Executive Director of the British Geological Survey (NERC). Data can be made available on request to satisfy open access requirements

\section{REFERENCES}

Abdoun T, Bennett V, Desrosiers T et al. (2013) Asset management and safety assessment of levees and earthen 
dams through comprehensive real-time field monitoring. Geotechnical and Geological Engineering 31(3): 833-843.

Allison RJ and Brunsden D (1990) Some mudslide movement patterns. Earth Surface Processes and Landforms 15(4): 297 311.

Anderson MG and Holcombe E (2013) Community-Based Landslide Risk Reduction: Managing Disasters in Small Steps. World Bank Publications, Washington, DC, USA, pp. 92-93.

Beard FD (1961) Predicting Slides in Cut Slopes. Western Construction, San Francisco 36: 72.

Cadman JD and Goodman RE (1967) Landslide noise. Science 158(3805): 1182-1184.

Chichibu A, Jo K, Nakamura M et al. (1989) Acoustic emission characteristics of unstable slopes. Journal of Acoustic Emission 8(4): 107-112.

Cruden D and Varnes DJ (1996) Landslide types and processes. In Landslides: Investigation and Mitigation. Transportation Research Board, Washington, DC, USA, Special Report 247, pp. 36-75.

Dasenbrock D (2014) Performance observations of MEMS ShapeAccelArray (SAA) deformation sensors. Geotechnical Instrumentation News June: 23-26.

Dijkstra TA and Dixon N (2010) Climate change and slope stability in the UK: challenges and approaches. Quarterly Journal of Engineering Geology and Hydrogeology 43(4): 371-385.

Dixon N and Spriggs M (2007) Quantification of slope displacement rates using acoustic emission monitoring. Canadian Geotechnical Journal 44(6): 966-976.

Dixon N and Spriggs M (2011) Apparatus and method for monitoring soil slope displacement rate. UK Patent Application GB 2467419A

Dixon N, Hill R and Kavanagh J (2003) Acoustic emission monitoring of slope instability: development of an active wave guide system. Proceedings of the Institution of Civil Engineers - Geotechnical Engineering 156(2): 83-95, http:// dx.doi.org/10.1680/geng.2003.156.2.83.

Dixon N, Spriggs MP, Meldrum P et al. (2012a) Field trial of an acoustic emission early warning system for slope instability. Landslides and Engineered Slopes: Protecting Society through Improved Understanding. CRC Press, Boca Raton, FL, USA, pp. 1399-1404.

Dixon N, Spriggs MP, Marcato G et al. (2012b) Landslide hazard evaluation by means of several monitoring techniques, including an acoustic emission sensor. Landslides and Engineered Slopes: Protecting Society through Improved Understanding (Ebahardt E, Fruses C, Turner K and Leroueil S (eds)). CRC Press, Boca Raton, FL, USA, pp. 1405-1411.

Dixon N, Spriggs MP, Smith A et al. (2014a) Quantification of reactivated landslide behaviour using acoustic emission monitoring. Landslides 2014: 1-12, doi 10·1007/s10346-014 0491-z.

Dixon N, Moore R, Spriggs MP et al. (2014b) Performance of an acoustic emission monitoring system to detect subsurface ground movement at Flat Cliffs, North Yorkshire, UK Proceedings of the IAEG XII Congress, Torino, Italy.

Dunnicliff J (1988) Geotechnical Instrumentation for Monitoring Field Performance. Wiley, Chichester, UK.

Fujiwara T, Ishibashi A and Monma K (1999) Application of acoustic emission method to Shirasu slope monitoring. In Slope Stability Engineering (Yagi N, Yamagami T and Jiang JC (eds)). Balkema, Rotterdam, the Netherlands, pp. 147150

Garga VK and Chichibu A (1990) A study of AE parameters and shear strength of sand. Progress in Acoustic Emission V: 129-136.

Gibson AD, Culshaw MG, Dashwood C et al. (2013) Landslide management in the UK - the problem of managing hazards in a 'low-risk' environment. Landslides 10(5): 599-610.

Glendinning S, Hall J and Manning L (2009) Asset-management strategies for infrastructure embankments. Proceedings of the Institution of Civil Engineers - Engineering Sustainability 162(2): 111-120, http://dx.doi.org/10.1680/ ensm.2009.162.2.111.

Hutchinson JN (1988) General report: morphological and geotechnical parameters of landslides in relation to geology and hydrogeology. Proceedings of the 5th International Symposium on Landslides, Lausanne, Switzerland, pp. 3-35.

Kane WF and Beck TJ (2000) Instrumentation practice for slope monitoring. Engineering Geology Practice in Northern California. Sacramento and San Francisco Sections, Association of Engineering Geologists, Zanesville, OH, USA.

Koerner RM, McCabe WM and Lord AE (1981) Acoustic emission behaviour and monitoring of soils. Acoustic Emission in Geotechnical Practice. American Society for Testing and Materials, West Conshohocken, PA, USA, ASTM STP 750, pp. 93-141.

Leroueil S (2001) Natural slopes and cuts: movement and failure mechanisms. Géotechnique 51(3): 197-243, http://dx.doi.org/ 10.1680/geot.2001.51.3.197.

Lord AE and Koerner RM (1974) Acoustic emission response of dry soils. Journal of Testing and Evaluation 2(3): 159-162.

Machan G and Beckstrand DL (2012) Practical considerations for landslide instrumentation. In Landslides and Engineered Slopes: Protecting Society Through Improved Understanding (Eberhardt E, Froese C, Turner K and Leroueil S (eds)). CRC Press, Boca Rato, FL, USA, vol. 2 pp. 1229-1234.

Michlmayr G, Cohen D and Or D (2012a) Sources and characteristics of acoustic emissions from mechanically stressed geologic granular media - a review. Earth-Science Reviews 112(3): 97-114.

Michlmayr G, Or D and Cohen D (2012b) Fiber bundle models for stress release and energy bursts during granular shearing. Physical Review 86(061307): 1-7.

Michlmayr G, Cohen D and Or D (2013) Shear-induced force fluctuations and acoustic emissions in granular material. Journal of Geophysical Research: Solid Earth 118(12): 60866098.

Mikkelsen PE (2003) Advances in inclinometer data analysis. In 
Field Measurements in Geomechanics: Proceedings of the 6th International Symposium, Oslo, Norway (Myrvoll F (ed.)). CRC Press, Boca Raton, FL, USA, pp. 1-13.

Mitchell RJ and Romeril PM (1984) Acoustic emission distress monitoring in sensitive clay. Canadian Geotechnical Journal 21(1): $176-180$.

Naemura S, Mitugu T, Nishikawa S et al. (1991) Acoustic emission of penetration experiments to judge soil condition. Journal of Acoustic Emission 10(1-2): 55-58.

Nakajima I, Negishi M, Ujihira M et al. (1991) Application of the acoustic emission monitoring rod to landslide measurement. Acoustic Emission/Microseismic Activity in Geologic Structures and Materials: Proceedings of the 5th Conference (Hardy HR (ed.)). Trans Tech, Dürnten, Switzerland, pp. $1-15$.

Petley DN, Mantovani F, Bulmer MH et al. (2005) The use of surface monitoring data for the interpretation of landslide movement patterns. Geomorphology 66(1): 133-147.

Rouse C, Styles P and Wilson SA (1991) Microseismic emissions from flowslide-type movements in South Wales. Engineering Geology 31(1): 91-110.

Schuster RL and Krizek RJ (1978) Landslides Analysis and Control. Transportation Research Board, Washington, DC, USA, Special Report 176.

Shiotani T and Ohtsu M (1999) Prediction of slope failure based on AE activity. In Acoustic Emission (Vahaviolos SJ (ed.)).
American Society for Testing Materials, West Conshohocken, PA, USA, Standards and Technology update ASTM STP 1353, pp. 157-172.

Simeoni L and Mongiovì L (2007) Inclinometer monitoring of the Castelrotto landslide in Italy. Journal of Geotechnical and Geoenvironmental Engineering 133(6): 653-666.

Skempton AW (1964) Long-term stability of clay slopes. Fourth Rankine Lecture. Géotechnique 14(2): 77-101, http:// dx.doi.org/10.1680/geot.1964.14.2.77.

Smith A and Dixon N (2014) Quantification of landslide velocity from active waveguide-generated acoustic emission. Canadian Geotechnical Journal doi 10·1139/cgj-2014-0226.

Smith A, Dixon N, Meldrum P et al. (2014a) Acoustic emission monitoring of a soil slope: comparisons with continuous deformation measurements. Géotechnique Letters 4(4): 255 261, http://dx.doi.org/10.1680/gedett.14.00053.

Smith A, Dixon N, Berg N et al. (2014b) Listening for landslides: method, measurements and the Peace River case study. Geohazards 6, Kingston, Ontario, Canada.

Smith A, Dixon N, Meldrum P et al. (2014c) Inclinometer casings retrofitted with acoustic real-time monitoring systems. Ground Engineering, October.

Spriggs MP (2005) Quantification of Acoustic Emission from Soils for Predicting Landslide Failure. $\mathrm{PhD}$ thesis, Civil and Building Engineering, Loughborough University, Loughborough, UK.

\section{WHAT DO YOU THINK?}

To discuss this paper, please email up to 500 words to the editor at journals@ice.org.uk. Your contribution will be forwarded to the author(s) for a reply and, if considered appropriate by the editorial panel, will be published as a discussion in a future issue of the journal.

Proceedings journals rely entirely on contributions sent in by civil engineering professionals, academics and students. Papers should be 2000-5000 words long (briefing papers should be 1000-2000 words long), with adequate illustrations and references. You can submit your paper online via www.icevirtuallibrary.com/content/journals, where you will also find detailed author guidelines. 